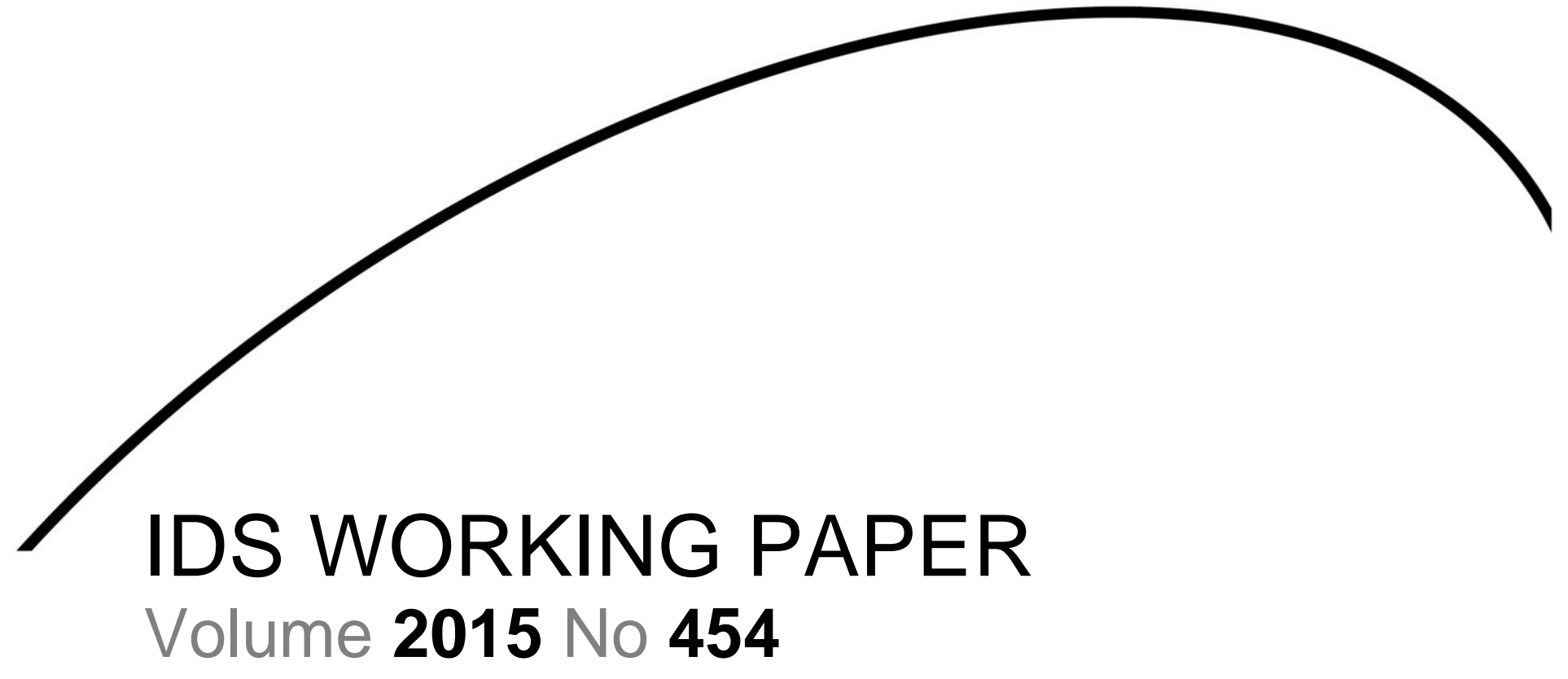

\title{
Building a Resilient Health System: Lessons from Northern Nigeria
}

Andrew McKenzie, Ahmad Abdulwahab, Emmanuel Sokpo and Jeffrey W. Mecaskey

April 2015 
Building a Resilient Health System: Lessons from Northern Nigeria

Andrew McKenzie, Ahmad Abdulwahab, Emmanuel Sokpo and Jeffrey W. Mecaskey

First published by the Institute of Development Studies in April 2015

IDS Working Paper 454

(C) Institute of Development Studies 2015

ISSN: 2040-0209 ISBN: 978-1-78118-229-1

A catalogue record for this publication is available from the British Library.

All rights reserved. Reproduction, copy, transmission, or translation of any part of this publication may be made only under the following conditions:

- with the prior permission of the publisher; or

- with a licence from the Copyright Licensing Agency Ltd., 90 Tottenham Court Road, London W1P 9HE, UK,

or from another national licensing agency; or

- under the terms set out below.

This publication is copyright, but may be reproduced by any method without fee for teaching or nonprofit purposes, but not for resale. Formal permission is required for all such uses, but normally will be granted immediately. For copying in any other circumstances, or for reuse in other publications, or for translation or adaptation, prior written permission must be obtained from the publisher and a fee may be payable.

\section{Available from:}

Communications and Engagement Unit, Institute of Development Studies, Brighton BN1 9RE, UK

Tel: +44 (0) 1273915637 Fax: +44 (0) 1273621202

E-mail: bookshop@ids.ac.uk

Web: www.ids.ac.uk/publications

IDS is a charitable company limited by guarantee and registered in England (No. 877338) 


\title{
Building a Resilient Health System: Lessons from Northern Nigeria
}

\author{
Andrew McKenzie, Ahmad Abdulwahab, Emmanuel Sokpo and \\ Jeffrey W. Mecaskey
}

\section{Summary}

The overarching aim of this paper is to address the issue of building resilient health systems in the context of the Ebola outbreak in West Africa which has brought renewed attention to this challenge. The paper highlights insight gained from two decades work creating resilient health systems in Nigeria-in Northern Nigeria in particular. ${ }^{1}$ In highlighting how the "simple" basics of outbreak control tie into larger, complex adaptive systems, this paper summarises key learning from the Nigerian experience as a basis for suggesting both how such outbreaks can be averted in the future and how sustainable development goals around eliminating excess mortality and improving health equity can be realised in practice.

Building resilient health systems requires:

- $\quad$ a set of interventions that cover all the six (plus 1) health systems strengthening (HSS) building blocks;

- $\quad$ resources (financial and human) that can flexibly respond to challenges and opportunities;

- investment over a long period of time; and

- a methodology that combines an appropriate and ongoing engagement approach, integrating governance reform with systems strengthening and building policy-maker and community support for systems strengthening

In many situations HSS interventions only address one or more of the building blocks and their results tend to be short-lived, because different elements of the system are integrally inter-connected and inter-dependent. For sustainability and impact, whole systems need to be addressed.

In the programmes the team worked on there was the ability to work widely across the health system, addressing issues of governance, finance, institutional management, demand and accountability, service delivery, etc.-frequently at the same time. The impact is shown in the results described in this paper.

Based on the experience from Nigeria and other contexts, key steps that should be taken to build resilient health systems include:

- Ongoing policy dialogue to build political commitment from affected country governments and international organisations and governments

- Development of comprehensive and realistic plans to build health systems that are resilient to anticipated shocks and disruptions in the affected countries

- Reorganisation of health services to reduce fragmentation

- Development and implementation of a minimum service package approach

- Mobilisation of experienced technical assistance to build the needed resilient health systems

This paper builds on work undertaken by Health Partners International in Nigeria, as well as South Sudan, particularly the Partnership for Reviving Routine Immunisation Northern Nigeria, Maternal, Newborn Child Health (PRRINN-MNCH) with support from UKAid from the UK Government and the Dept. of State of the Norwegian Government. 
- Strengthening specific components of all six (plus one) HSS building blocks

- Agreement on joint review and monitoring systems to promote accountability and transparency.

Thus, in building the health system in post Ebola West Africa, experience in the fragile circumstances of Northern Nigeria and South Sudan point to the importance of systems thinking even before the epidemic has abated. Thinking deliberately about how the health system in these countries might behave, given the complex adaptive systems analysis, should inform activities to address the epidemic and lay the foundation for post epidemic health systems strengthening.

Keywords: resilient health systems; Ebola; complex adaptive systems; health systems strengthening

Andrew McKenzie a South African health manager with 30 years of experience gained in Africa (predominantly South Africa and Nigeria) chairs the board of the HPI Institute and is a Senior Partner at Health Partners International. He has extensive experience in capacity building and facilitation and an excellent understanding of managing health systems and services, health sector reform and district development in sub-Saharan Africa. Qualifications include a medical degree, a Masters in public health and a post-graduate diploma in adult education.

Ahmad Abdulwahab a Nigerian physician has worked in and managed health services for over 15 years, most recently as the National Programme Manager of PRRINN-MNCH, is a Director of NPHD Ltd. Having worked with programmes at the national, state and facility level, he has practical knowledge and understanding of public health and the health sector in Nigeria, especially in the North, and of the workings of government, governance and HausaFulani society more widely.

Emmanuel Sokpo a Nigerian physician with extensive postgraduate training related to health system strengthening is Managing Director of NPHD Ltd and a Senior Partner at Health Partners International. With extensive experience in health policy, strategy and planning as well as in the reorganisation and management of primary and secondary health services, he is a seasoned health administrator and an experienced project manager with expertise in institutional capacity building, supply management and logistics; maternal, newborn and child health programming, neglected tropical disease and quality assurance/improvement in health.

Jeffrey W. Mecaskey an American health and political economist serves as HPI Institute secretary and is a partner at Health Partners International. He has more than 30 years' experience with a focus on health and political economics, health policy and management. He has overseen research portfolio development and management as well as planning, implementation and evaluation of health programmes. 


\section{Contents}

Summary 3

Keywords and author notes 4

$\begin{array}{ll}\text { Acknowledgements } & 6\end{array}$

$\begin{array}{ll}\text { Acronyms } & 6\end{array}$

1 Introduction $\quad 7$

2 Methodology $\quad 8$

3 Application of methodology 10

i Context - the Nigerian Health System 10

$\begin{array}{ll}\text { ii } & 12\end{array}$

4 Results $\quad 16$

$5 \quad$ Lessons learnt $\quad 18$

$\begin{array}{ll}\text { i An appropriate and ongoing engagement approach } & 19\end{array}$

ii Integrating governance reform with systems strengthening 20

iii Building policymaker and community support for systems and
strengthening

6 Way forward $\quad 24$

$\begin{array}{llr}7 & \text { Conclusion } & 25\end{array}$

$\begin{array}{lr}\text { References } & 27\end{array}$ 


\section{Acknowledgements}

We are very grateful to the management and staff of the PATHS and PRRINN-MNCH programmes in Nigeria and the staff of DFID, Nigeria for supporting the work from which this paper emerged. The work was conducted for over a decade under the auspices of Health Partners International. Further comments are welcome and can be sent to Andrew McKenzie at a.mckenzie@hpiinstitute.org

\section{Acronyms}

$\begin{array}{ll}\text { ABM } & \text { Agent-based Modelling } \\ \text { ANC } & \text { Antenatal Care } \\ \text { CAS } & \text { Complex Adaptive Systems } \\ \text { CLD } & \text { Causal Loop Diagrams } \\ \text { DFID } & \text { Department for International Development } \\ \text { DHIS2 } & \text { District Health Information System 2 } \\ \text { DOC } & \text { Drivers of Change } \\ \text { EOC } & \text { Emergency Obstetric Care } \\ \text { FMS } & \text { Financial Management Systems } \\ \text { GAVI } & \text { Global Alliance for Vaccines and Immunisation } \\ \text { HHS } & \text { Household Survey } \\ \text { HMIS } & \text { Health Management Information System } \\ \text { HPI } & \text { Health Partners International } \\ \text { HR } & \text { Human Resource } \\ \text { HRIS } & \text { Human Resource Information System } \\ \text { HSDP } & \text { Health Systems Development Programme } \\ \text { HSS } & \text { Health Systems Strengthening } \\ \text { IMR } & \text { Infant Mortality Rate } \\ \text { LGA } & \text { Local Government Authority } \\ \text { LLIN } & \text { Long Lasting Insecticidal Net } \\ \text { M\&E } & \text { Monitoring and Evaluation } \\ \text { MAPS } & \text { Malaria Action Programme for States } \\ \text { MDA } & \text { Ministries, Departments, Agencies } \\ \text { MDG } & \text { Millennium Development Goals } \\ \text { MNCH } & \text { Maternal, Newborn and Child Health } \\ \text { MSP } & \text { Minimum Service Package } \\ \text { NICS } & \text { National Immunisation Cluster Survey } \\ \text { NPHCDA } & \text { National Primary Health Care Development Agency } \\ \text { NPM } & \text { National Programme Manager } \\ \text { ORS } & \text { Oral Rehydration Solution } \\ \text { PATHS } & \text { Partnership for Transforming Health Systems } \\ \text { PHC } & \text { Primary Health Care } \\ \text { PHCUOR } & \text { Primary Health Care Under One Roof } \\ \text { PIPA } & \text { Participatory Impact Pathways Analysis } \\ \text { PLAMAHS } & \text { Planning and Management of Assets in Health Services } \\ \text { PRRINN- } & \text { Partnership for Reviving Routine Immunisation in Northern Nigeria } \\ \text { MNCH } & \\ \text { R4D } & \text { Research for Development } \\ \text { SBA } & \text { Skilled Birth Attendant } \\ \text { SHC } & \text { Secondary Health Care } \\ \text { SHMB } & \text { State Hospital Management Board } \\ \text { SMOH } & \text { State Ministry of Health } \\ \text { SPHCDA/B } & \text { State Primary Health Care Development Agency/Board } \\ \text { U5MR } & \text { Under Five Mortality Rate } \\ \text { WHO } & \text { World Health Organisation } \\ & \end{array}$


Decades of neglect of fundamental health systems and services mean that a shock, like ... a disease run wild, can bring a fragile country to its knees. These systems cannot be built up during a crisis. Instead, they collapse. ...Deadly pathogens exploit weak health systems...It is, however, important to understand one point: these deaths are not "collateral damage". They are all part of the central problem: no fundamental public health infrastructures were in place, and this is what allowed the virus to spiral out of control. In the simplest terms, this outbreak shows how one of the deadliest pathogens on earth can exploit any weakness in the health infrastructure, be it inadequate numbers of health care staff or the virtual absence of isolation wards and intensive care facilities throughout much of sub-Saharan Africa.

\author{
Margaret Chan \\ http://www.who.int/csr/disease/ebola/ebola-6-months/lessons/en/
}

But the reality is this: The Ebola crisis today is a reflection of long-standing and growing inequalities of access to basic health care. Guinea, Liberia and Sierra Leone do not have the staff, stuff and systems required to halt the outbreak on their own. According to its ministry of health, before the outbreak, Liberia had just 50 doctors working in public health facilities serving a population of 4.3 million.

Paul Farmer and Jim Yong Kim

http://www.washingtonpost.com/opinions/whats-missing-in-the-ebola-fight-in-westafrica/2014/08/31/19d6dafc-2fb4-11e4-9b98-848790384093_story.html

\title{
1. Introduction
}

The classical approach to epidemic infectious disease outbreak control is grounded in the principles of epidemiology and clinical medicine. Epidemic prevention and outbreak control are reliant on a coordinated response across the range of key areas delineating the back bone of the health system: surveillance; case identification, contact tracing and containment; clinical management and meticulous infection control. Such a coordinated response implies sectoral governance including investment in, and functioning of, infrastructure, trained personal, essential medicines and links to its client population. The ability to coordinate this response is a fundamental marker of health system resilience.

In Nigeria, the health system was not overwhelmed by Ebola. Disease surveillance worked well: index cases were identified, contacts traced and assessed for symptoms and signs of Ebola and, where appropriate, quarantined. Political capital was mobilised and significant financial resources were released. The government communicated regularly and repeatedly with media and the public at large, updating all on the state of play. Although the health system was not fully tested because of these measures, it was resilient enough to withstand and contain an initial battering of the Ebola virus.

The focus of the discussion in this paper is not on analysing Nigeria's effective response to the Ebola crisis, rather it is on understanding the importance of resilience in health systems as a needed prerequisite for containing a crisis such as Ebola.

The concept of resilience is gaining credence as both a both a means, and an end, for promoting a robust health system capable of maintaining service delivery in contexts of acute or chronic crisis. 
Resilience is the capacity of any entity -an individual, a community, an organization, or a natural system - to prepare for disruptions, to recover from shocks and stresses, and to adapt and grow from a disruptive experience.

(Rodin 2014)

Resilience can be seen as the long-term capacity of a system, in our case the health system, to deal with change and continue to develop. Folke et al (in Zhang et al 2014) argue that adaptation and transformation are essential for maintaining system resilience. They view adaptability as the capacity of actors in a system to influence resilience; and transformability as the capacity to create a fundamentally new system that functions despite disruption. They differentiate two types of transformation: forced transformation happens at a scale beyond the influence of local actors and is imposed by external forces contrasted with transformation that is the deliberately initiated transformational process by people involved at multiple levels and can lead to feedback effects that conclude in whole system change. Identifying key sources of vulnerability and health systems structures and designs that promote resilient functioning can inform policy-making across a broad range of settings (Ager et al 2014).

The paper draws heavily on over two decades experience in building resilient health systems through strengthening adaptability and initiating transformation in individuals, system and institutions by the authors in Nigeria and more recently in South Sudan. Strengthening health systems and building resilience is a slow process that can only be achieved over the long term with a methodology for systems strengthening that appreciates the interactions of components of the system and works with local stakeholders.

\section{Methodology}

Insight generated by addressing the complex adaptive nature of health systems has increasingly been applied to health policy development, health systems reform and health systems strengthening (Paina et al 2012). In this approach, the health sector is seen as an open system in which different components are interdependent and can influence each other in a non-linear fashion (Pourbohloul et al 2011). Non-linearity and the notion of emergent behaviour (i.e. behaviour that is not a property of any of the components of that system, but which results from the interactions of the components) mean that a change in one part of the system can have unpredictable 'ripple effects' in others (Dattee and Barlow 2010). In addition, the complex adaptive lens approach reinforces notions including:

- feedback loops that feed into the system and explain how small changes can grow into large consequences that can reinforce a particular outcome or lead the system to go back to an original state, what is called 'balancing' or goal-seeking loops;

- $\quad$ path dependence which refers to non-reversible processes with similar starting points that can have very dissimilar outcomes, resulting from different contexts and histories and different choices at key points;

- $\quad$ phase transitions (when 'tipping points' are reached and initiate change); and,

- $\quad$ scale-free networks refer to the formation of influential hubs or individuals that can shift the focus and power of networks by exerting higher influence on other actors in the network through their multiple interconnectedness (Paina et al 2012; Varghese et al 2014).

Systems thinking is, foremost, a way of thinking that views components and systems as closely interrelated and connected to each other, believing that to strengthen systems requires analysing interrelationships and interactions within and between systems (Adam 2014; Peters 2014). And in Nigeria we have seen early signs of improvement as 
policymakers and health system reformers adopt a whole-system approach to ensure changes at one level support rather than impede changes at another.

The World Health Organisation's report Systems Thinking for Health System Strengthening, (WHO 2009 in De Savigny and Taghreed 2009) was heavily influenced by acknowledging the complex adaptive nature of health systems, and recognises non-linearity and interdependence in a proposed framework for health system strengthening.

a complex adaptive system lens helps to uncover the 'real' drivers for change (Varghese et al 2014)

The ideas of complex adaptive systems theory are closely linked to the political economy Drivers of Change (DOC) approach adopted by the UK Department for International Development (DFID) (Heymans and Pycroft 2005) which has significantly influenced development and health system reform work, especially in Nigeria. The DOC approach conceptualises three interacting components operating within any system and influencing change within it:

\section{Conceptual model for understanding Drivers of Change}

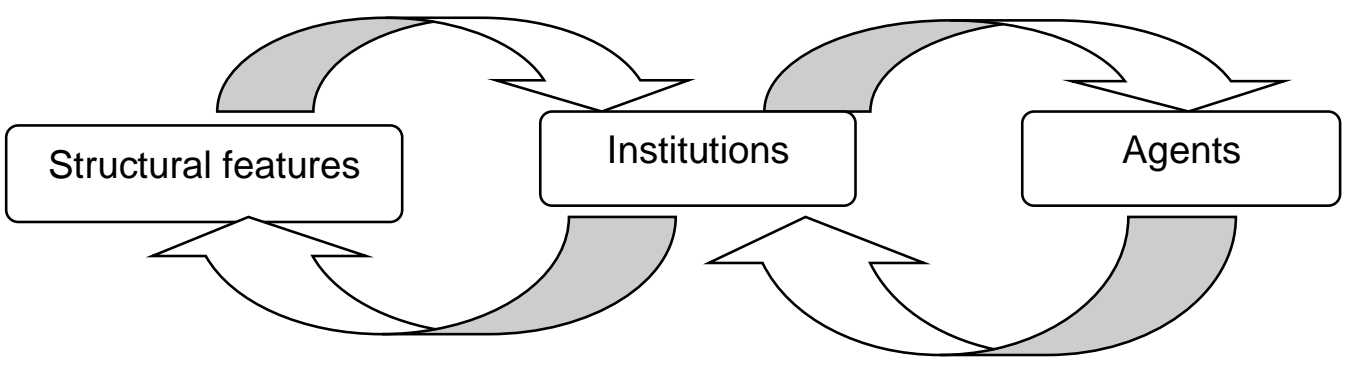

Source: DFID (2004)

Structural features - the history of the state/organisation; natural and human resources; economic and social structures; demographic changes; regional issues; globalisation, trade and investment; urbanisation

Institutions - the informal and formal rules, such as political and public administration processes, that determine the realm of possible behaviour by agents

Agents - individuals and organisations pursuing particular interests: the political elite; civil servants; political parties; local government; the judiciary; the military; faith groups; trade unions; civil society groups; the media; the private sector; academics; donors

The DOC analytical approach examines the mechanisms through which power is transacted within society and the health system (Leftwich 2006; Haider and Rao 2010). The DOC approach informed the political economy assessments undertaken by DFID programmes at federal and state level in Nigeria, which led to a deeper understanding of the structural features, the power relations, the institutions (particularly the informal rules) and the agents operating in the health sector (Anyebe et al 2005). The political economy assessments assisted in the evaluation of different policy options and initiatives, and the identification of levers to advocate for, and implement, particular policy options or initiatives. This is very similar to the approach advocated by practitioners who see health systems as complex adaptive systems (Dattee 2010). ${ }^{2}$

The political economy assessments highlighted key challenges in addressing HR issues such as maldistribution of health workers and ghost workers. While the recommendation was 
to leave this alone, this was seen as sufficiently key for the PRRINN-MNCH (Partnership for Reviving Routine Immunisation in Northern Nigeria - Maternal, Newborn and Child Health) programme to tackle it. Because of the challenges, a broad-based high level approach was adopted that included:

- introducing a human resource (HR) information system (HRPlanner and HRAdmin) to allow for HR data to be captured and analysed to illustrate the enormity of the problem

- establishing a HR committee (in most cases chaired by the Chief of Staff) that included a significant number of senior public servants with good links to the key politicians, to drive the HR reform process

- strengthening HR departments/units within the State Ministries of Health to enable them to provide the necessary administrative support for HR reform processes

- introducing institutional/structural reforms, such as the Gunduma system or bringing $\mathrm{PHC}$ under one roof, to enable HR reform to be part of a wider reform initiative

- ongoing communication and advocacy to key political and community leaders.

Political economy assessments are one of a basket of methods and tools used by complex adaptive systems practitioners that include agent-based modelling (ABM), network analysis (or social network analysis), scenario planning, systems dynamics modelling, realist evaluation, policy analysis, causal loop diagrams (CLDs), innovation (or change management) history, participatory impact pathways analysis (PIPA), network mapping, social network analyses, and process mapping (Peters 2014; Adam 2014).

Both complex adaptive systems theory and the DOC approach to political economy see the health system as a whole system. Understanding the context in which potential change happens is vital for any new policy/initiative to be adopted. This requires a deep understanding of the structures, institutions and agents operating within the system.

The complex adaptive systems lens, the drivers of change approach and resilience thinking have all influenced the work reported on in this paper.

\section{Application of methodology}

\section{i) Context - the Nigerian Health System}

In the Nigerian constitution, health is a concomitant responsibility of the three tiers of government--the Federal, the State and the Local Government Area (LGA) (Zhou 2005; Freinkman 2007; Barron et al 2007). The functional delineation of roles and responsibilities among these three tiers is not well specified (Khemani 2005; Barron 2007). In principle, the Federal level is responsible for tertiary care, the State level for secondary care and the LGA level for primary health care. However, the reality on the ground is different especially as the policy is not backed up with adequate legislation, financing or regulatory momentum. Beyond the public sector, there are poorly regulated markets of non-state providers, including professors leading research-based, world class tertiary clinical care facilities, private pharmacists providing diagnostic and treatment services, itinerant patent medicine vendors, and a range of traditional healers and unconventional service providers.

Following independence in 1960, health services were the responsibility of the Nigerian government at the Federal and Regional levels. From 1966, as states developed, there was some delegation of power and authority (administrative decentralisation) to State Health Management Boards (SHMBs). Following Alma Ata and the emphasis on primary health care 
(PHC), Nigeria devolved PHC services in the late 1980s to the LGA level (Khemani 2005) (political decentralisation).

The National Primary Health Care Development Agency (NPHCDA) was created in 1992 to support the process of decentralisation and strengthening PHC services. At time of writing a number of states have established State Primary Health Care Agencies or Boards (SPHCA/Bs) to strengthen the decentralisation; and the share of sub-national budget spending (i.e. at state and LGA levels) in the consolidated budget doubled, increasing from 23 percent in 1999 to 46 percent in 2005 (Freinkman 2007).

Despite efforts to rationalise sectoral stewardship and service provision, the health system remains fragmented with elements of centralisation juxtaposed with decentralisation (Barron 2007; Freinkman 2007; Enyimayew 2007; Federal Ministry of Health 2004 - 2007; McKenzie 2014):

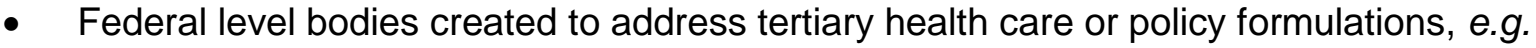
NPHCDA and National Programme on Immunisation, often strayed into implementation including building and establishing PHC facilities;

- There is confusion about the types of medical facilities that may be developed and managed by each level of government. For example, in many states, State Ministries of Health while managing secondary health care hospitals as well as establishing tertiary care/teaching hospitals, also built and managed PHC facilities;

- In human resource management, the state-level Local Government Service Commission is responsible for the more senior PHC facility staff, while the LGAs manage the lower level health workers in the same facilities;

- While finance is nominally devolved in block grants to both states and LGAs, state governments established joint accounts in which state and LGA financial resources are placed, with control of these accounts resting with the state Governor alone (Zhou, 2005); and,

- At each level there exists a myriad of different departments, directorates and units with overlapping responsibilities impeding coordinated planning and delivery. For example, at state and LGA level, multiple bodies are involved in health care. At state level, services can be provided by the State Ministry of Health (SMOH), the State Hospital, or Health, Management Board (SHMB), the State PHC Development Agency (SPHCDA), while financial and human resource allocation and management can be through other bodies.

The multitude of different agents and responsibilities makes coordinated management across the Ministry technically difficult. The scale of the problem intensifies between the tiers, because many of these units have been established in order to get involved in the delivery of services which reasonably should be the responsibility of PHC under local governments. For example the NPHCDA is intended to (and does) carry out supplemental immunisation campaigns against vaccine preventable diseases including Polio, but for effective and sustained immunisation services, routine immunisation needs to be strengthened within the responsibilities of $\mathrm{PHC}$ units located and managed within the jurisdiction of local governments.

In the early 2000 s, following the return to democracy after years of military rule, there was a renewed interest in health policy development and legislation (Health Sector Reform Program 2004; Revised National Health Policy 2004; National Health Bill 2011). At Federal level, the revised National Health Policy was developed and draft health legislation formalised. The policy and legislation better defined the role of the three tiers of government and encouraged the formation of State Primary Health Care Boards. These Boards were to be substantially funded (Barron 2007). Unfortunately, the legislation (although passing through both Houses of Parliament) has not yet been signed into law. 
Recognising the need for reform to address the fragmented nature of the health care delivery system, several states have explored the development of district health systems or 'Bringing PHC Under One Roof' (PHCUOR). Different approaches were adopted in different states. In addition, the possibility of the funding that would flow from the Federal health Act $(50 \%$ of the proposed funds would be allocated to the SPHCA/Bs) drove policy and legislative changes in many states.

In summary, the Nigerian heath services have been, and still are characterised by weak governance and underinvestment including poor budgeting, and limited supply of basic medicines and equipment (Federal Ministry of Health 2010). The Nigerian health system is under budgeted and fragmented (Federal Ministry of Health 2010). Within the public sector, only $7 \%$ of federal resources are dedicated to health. Tertiary, secondary and primary levels are funded through separate channels, which are not adequately budgeted, monitored or accountable to one another (DFID PQQ 2013). The system is poorly regulated with a weak financial safety net for the poor; communities are not empowered to take responsibility for their health and accountability systems are also very weak.

The results of this litany of dysfunction is reflected in Nigeria's poor indicators related to health access and outcomes. Despite its place as the "richest country in Africa," major indices for populations in Southern Nigeria are far worse than those of their league table peers. And in Northern Nigeria, we find some of the world's worst indicators across the population and particularly in maternal, newborn and child health.

\section{ii) Approaches used on the programmes}

The experience of two major health systems strengthening programmes in Nigeria that the team has been involved in, the Partnership for Reviving Routine Immunisation in Northern Nigeria-Maternal Newborn and Child Health initiative (PRRINN-MNCH) and the Partnership for Transforming Health Systems (PATHS), are used as examples to illustrate our understanding of strengthening and building resilience health systems in a fragile environment. The PATHS programme ran from 2002 to 2007 in six states across Nigeria. The PRRINN-MNCH programme was based in Northern Nigeria from 2008 to $2014 .{ }^{3}$ The programme covered four states with a population approaching 20 million. ${ }^{4}$

Using the complex adaptive systems lens, the drivers of change model and resilience thinking, effective approaches that emerge largely from our work in Nigeria, include: an appropriate and ongoing engagement approach; integrating governance reform with systems strengthening; and building policy-maker and community support for systems strengthening.

Before describing the results and the lessons learnt from the approaches that we have adopted, the table below illustrates how the principles of the complex adaptive systems theory were effected in Nigeria. Two activity examples are used to illustrate this - "Bringing PHC under one roof" and the work on strengthening the GAVI (Global Alliance for Vaccines and Immunisation) fund.

In recent years Northern Nigeria has been affected by the Boko Haram insurgency which has impacted on programmes particularly in the North-East and in the PRRINN-MNCH programme in Yobe state. However, the use of local staff has minimised the impact.

4 For more details on the PRRINN-MNCH programme see http://www.prinn-mnch.org/resources-reports-annual.html 
Table: Illustrating how the CAS approach influenced initiatives

\begin{tabular}{|c|c|c|}
\hline $\begin{array}{l}\text { Complex adaptive system } \\
\text { components }\end{array}$ & " Bringing PHC under one roof" & $\begin{array}{l}\text { Strengthening allocation of GAVI } \\
\text { Funds }\end{array}$ \\
\hline $\begin{array}{l}\text { Open systems and a whole system } \\
\text { approach } \\
\text { Seeing health systems as open systems } \\
\text { and policy developers/ health system } \\
\text { reformers need to adopt a whole system } \\
\text { approach, understanding that different } \\
\text { components of the health system are } \\
\text { interdependent. }\end{array}$ & $\begin{array}{l}\text { 1. Both the PATHS and PRRINN-MNCH } \\
\text { programmes were either conceived or } \\
\text { morphed into broad health systems } \\
\text { strengthening programmes. Activities } \\
\text { ranged from governance, through } \\
\text { systems and services to community } \\
\text { engagement and accountability. } \\
\text { 2. Both the PATHS and PRRINN-MNCH } \\
\text { programmes engaged government } \\
\text { departments other than the health } \\
\text { MDAs (Ministry, Department, Agency). } \\
\text { Note that the length of the programmes } \\
\text { (PATHS from 2002-2008 and PRRINN- } \\
\text { MNCH from 2006-2013) allowed for } \\
\text { sustained engagement. In addition, } \\
\text { significant technical assistance was } \\
\text { sourced from Ghana and Southern } \\
\text { Africa (which had followed similar } \\
\text { routes) and key PATHS staff and } \\
\text { advisors moved onto the PRRINN- } \\
\text { MNCH programme thus retaining } \\
\text { Nigerian institutional memory. }\end{array}$ & $\begin{array}{l}\text { 1. The realisation that both state } \\
\text { systems of accessing, spending and } \\
\text { retiring GAVI funds and federal level } \\
\text { processes and support needed to be } \\
\text { strengthened. One would not be } \\
\text { enough. }\end{array}$ \\
\hline $\begin{array}{l}\text { Non-linearity and emergent } \\
\text { behaviour } \\
\text { Non-linearity and the notion of emergent } \\
\text { behaviour (i.e. behaviour of a system } \\
\text { that is not a property of any of the } \\
\text { components of that system but a result } \\
\text { of the interactions of the components) } \\
\text { mean that a change in one part of the } \\
\text { system can have unpredictable ripple } \\
\text { effects in other parts of the system. }\end{array}$ & $\begin{array}{l}\text { 1. The key legislative changes in the } \\
\text { Gunduma or district system in Jigawa } \\
\text { meant that previously fragmented } \\
\text { management of financial and human } \\
\text { resources was transferred to the } \\
\text { Gunduma Health Services Board from } \\
\text { state and LGAs. The outcome was that } \\
\text { administrative management and } \\
\text { procedures were strengthened at the } \\
\text { expense of political power and control. }\end{array}$ & $\begin{array}{l}\text { 1. Strengthening state level GAVI } \\
\text { systems led to increased funding in the } \\
\text { northern states. This led to the } \\
\text { NPHCDA requesting assistance to } \\
\text { strengthen the federal level GAVI } \\
\text { systems. }\end{array}$ \\
\hline $\begin{array}{l}\text { Views from different levels } \\
\text { Another key property of complex } \\
\text { systems is the different structure that } \\
\text { the system has at different levels and } \\
\text { the need for policy makers to be aware } \\
\text { of the 'view' from the different levels. }\end{array}$ & $\begin{array}{l}\text { 1. The proposed policy changes would } \\
\text { lead to altered 'power' relations between } \\
\text { state and LGA politicians, between state } \\
\text { and LGA managers and between } \\
\text { politicians and administrators/ } \\
\text { managers. The 'views' of these } \\
\text { roleplayers at the different levels } \\
\text { needed to be factored in. This was done } \\
\text { through retreats, exposure to best } \\
\text { practices and advocacy/lobbying. } \\
\text { Ultimately, this has led to significant } \\
\text { 'repositioning'. }\end{array}$ & $\begin{array}{l}\text { 1. Once the federal level NPHCDA was } \\
\text { made aware of the challenges at state } \\
\text { level in accessing GAVI funds and the } \\
\text { changes brought by strengthening state } \\
\text { level processes, the NPHCDA was more } \\
\text { amenable to changing processes for } \\
\text { accessing the GAVI funds. }\end{array}$ \\
\hline $\begin{array}{l}\text { Feedback loops } \\
\text { Both positive and negative that influence } \\
\text { the pace and direction of change. }\end{array}$ & $\begin{array}{l}\text { 1. Initially there was scepticism to the } \\
\text { district development work. Following } \\
\text { positive results (e.g. the } 2010 \text { NICS data } \\
\text { - National Immunisation Cluster Survey) } \\
\text { there was renewed interest in the } \\
\text { concept. } \\
\text { 2. The unsigned Health Bill with a } \\
\text { significant carrot of funding if states } \\
\text { formed State PHC Development Boards } \\
\text { influenced the pace of state level } \\
\text { activities - the memo and } \\
\text { implementation guide filled a vacuum. }\end{array}$ & $\begin{array}{l}\text { 1. Increased frequency of accessing, } \\
\text { spending and retiring GAVI funds from } \\
\text { PRRINN-MNCH supported states led to } \\
\text { NPHCDA requesting assistance in } \\
\text { rolling out the methodology to other } \\
\text { states. }\end{array}$ \\
\hline $\begin{array}{l}\text { Path dependence } \\
\text { Processes that have similar starting } \\
\text { points can have very dissimilar } \\
\text { outcomes resulting from different } \\
\text { contexts and histories and different } \\
\text { choices at key bifurcations. }\end{array}$ & $\begin{array}{l}\text { 1. A key difference was the adoption of } \\
\text { either an integrated PHC system (e.g. } \\
\text { Yobe and Zamfara) or an integrated } \\
\text { PHC and secondary health care (SHC) } \\
\text { system (e.g. Enugu and Jigawa). This } \\
\text { was a combination of history/context } \\
\text { (e.g. Jigawa had no State Hospital } \\
\text { Management Board) and of different } \\
\text { choices at key moments (usually by the }\end{array}$ & $\begin{array}{l}\text { 1. Strengthening the GAVI system in } \\
\text { Jigawa led to the state strengthening } \\
\text { their systems for accessing other } \\
\text { federally controlled funds (e.g. in } 2010 \text {, } \\
\text { Jigawa accessed } 609 \text { million naira from } \\
\text { the MDG (Millennium Development } \\
\text { Goal) fund, } 75 \text { million naira from the } \\
\text { NHIS (National Health Insurance } \\
\text { Scheme) fund and } 40 \text { million from the }\end{array}$ \\
\hline
\end{tabular}




\begin{tabular}{|c|c|c|}
\hline & $\begin{array}{l}\text { state Governor). } \\
\text { 2. At critical bifurcations, key activities } \\
\text { included 'time-out' for reflection and } \\
\text { exposure to success stories (e.g. } \\
\text { Ghana). This assisted in decision } \\
\text { making. } \\
\text { Note that both the PATHS and PRRINN- } \\
\text { MNCH programmes have always } \\
\text { advocated a not-one-size-fits-all } \\
\text { approach. }\end{array}$ & $\begin{array}{l}\text { HSDP (Health Services Development } \\
\text { Programme) fund). This was not the } \\
\text { case in other states (or not to the same } \\
\text { extent). }\end{array}$ \\
\hline $\begin{array}{l}\text { Scale-free networks } \\
\text { Incorporating focal points - including key } \\
\text { powerful people - that can dominate a } \\
\text { structure. }\end{array}$ & $\begin{array}{l}\text { 1. Key roleplayers were part of the } \\
\text { PRRINN-MNCH team (e.g. previous } \\
\text { Permanent Secretary for Health). In } \\
\text { addition, the executive director of } \\
\text { NPHCDA (and later the Minister) was an } \\
\text { early convert and eventually drove the } \\
\text { process. } \\
\text { 2. At state level, similar people were } \\
\text { identified and supported. }\end{array}$ & $\begin{array}{l}\text { 1. A key focal point was convincing the } \\
\text { NPHCDA GAVI office that states in the } \\
\text { north could make the system work - } \\
\text { accessing, spending and retiring the } \\
\text { funds. This opened the door to changing } \\
\text { and strengthening the processes. }\end{array}$ \\
\hline $\begin{array}{l}\text { Phase transitions } \\
\text { When critical points - 'tipping points' - } \\
\text { are reached and initiate change. }\end{array}$ & $\begin{array}{l}\text { 1. For many states in the north, the } \\
\text { critical point came with the NICS } \\
\text { (National Immunisation Cluster Survey) } \\
2010 \text { data that showed how improved } \\
\text { Jigawa was (other data has confirmed } \\
\text { this). This led other states to explore } \\
\text { variations of the Gunduma approach. } \\
\text { 2. The decision by the NCH in May } 2011 \\
\text { to endorse the memo and 'Bringing PHC } \\
\text { under one roof' implementation guide } \\
\text { and to encourage states to form } \\
\text { SPHCBs initiated a rush to create these } \\
\text { Boards. }\end{array}$ & $\begin{array}{l}\text { 1. The critical point was when the } \\
\text { NPHCDA GAVI unit saw how states } \\
\text { who had previously not accessed GAVI } \\
\text { funds more than once, now doing this. } \\
\text { The GAVI unit then wanted assistance } \\
\text { to roll this out to other states. }\end{array}$ \\
\hline
\end{tabular}

On both programmes, underpinning the success was the adoption of the six health systems strengthening (HSS) building blocks as enunciated by the $\mathrm{WHO}^{5}$ in strengthening health care systems, with a focus on PHC systems, inclusive of district hospitals. To the usual six pillars has been added a seventh (community engagement). ${ }^{6}$ 


\section{Examples of activities under the six (+one) HSS pillars in the PRRINN-MNCH programme}

\section{Pillar 1: Service delivery}

- Integrated and strengthened $\mathrm{MNCH}$ services through the adoption of the WHO recommended Emergency Obstetric Care (EOC) cluster approach to service delivery.

- Enhanced $\mathrm{MNCH}$ health service with focus on minimum packages of care and community links through introduction of the Community Based Service Delivery model.

\section{Pillar 2: Health workforce}

- Enhanced technical skills for provision of $\mathrm{MNCH}$ services through regular training and supportive supervision. Thousands of health workers have been trained in the four states on different aspects of $\mathrm{MNCH}$ services.

- Expanded systems for integrated supportive supervision (management) and technical supportive supervision (clinical) at state and local government area levels instituted in all four states.

- Establishment and maintenance of a Human Resource Information System allowing for auditing and improved distribution of staff.

- Development of policies that produce short to long term HR plans to guide investment in human resources

- Development of a national task shifting policy and implementation guidelines to address the critical workforce gap and maldistribution

\section{Pillar 3: Information}

- Enhanced access to MNCH data with the introduction of DHIS2 (District Health Information System) software and data available on the internet.

- Improved data and analysis through tools and regular data quality audits. Data quality and use has improved significantly.

- Development of the Nahuche Health Demographic Surveillance System site to provide evidence-based outcomes of piloted interventions through operations research.

Pillar 4: Medical products, vaccines and technology

- Improved availability of drugs with a sustainable drug supply system.

- Increased capacity for building and equipment improvement, procurement, training and maintenance through introducing the Planning and Management of Assets in Health Services (PLAMAHS) system.

- Enhance the provision, use and promotion of the culture of infection control systems in health services

\section{Pillar 5: Health financing}

- Expanded availability of funds for PHC through the establishment of a pooled funding mechanism in Jigawa and a Basket Fund in Zamfara.

- Strengthening the public FMS by building the capacity of the planning and budgeting team to budget, track and account for resources.

- Established community based financing safety nets for the poor and $\mathrm{MNCH}$ emergencies

\section{Pillar 6: Leadership and governance}

- Improved coordination of PHC services through the 'Bringing PHC under one roof' strategy and incorporation of this strategy into Nigerian national policy and state legislation.

- Enhanced participatory policy making, planning, budgeting and reviews via support to stateled, health-sector wide processes. More efficient processes free up funds for the PHC system.

- Effective performance reviews monitor progress against targets and guide decision making

+ one pillar: Community engagement

- Tackled the first and second delays to accessing emergency maternal health services through an integrated community engagement approach which addressed key barriers simultaneously to establish sustainable community response systems.

- Increased standing permission for mothers to access obstetric care services.

- Extended community voice on health issues and promoted greater accountability of health providers and managers via an emphasis on facility health committees.

- Focused attention on clustering of child morbidity/mortality with strategies to address both supply and demand. 


\section{Results}

Two health systems strengthening programmes in Nigeria that the team has been involved in, the Partnership for Reviving Routine Immunisation in Northern Nigeria-Maternal Newborn and Child Health initiative (PRRINN-MNCH) and the Malaria Action Programme for States (MAPS) are used to illustrate changes.

Independent assessment of the PRRINN-MNCH programme has estimated programmeassociated if not attributable ${ }^{7}$ change across a range of key output, outcome and health indicators.

The follow examples serve to highlight the type of change possible. On the PRRINN-MNCH programme (PRINN-MNCH 2013), in terms of output, attendance at ANC and births by SBAs more than doubled between 2009 (baseline survey) and 2013 (endline survey). Though the data are incomplete, there is some suggestion of an associated improvement in maternal mortality ratio over the same period.

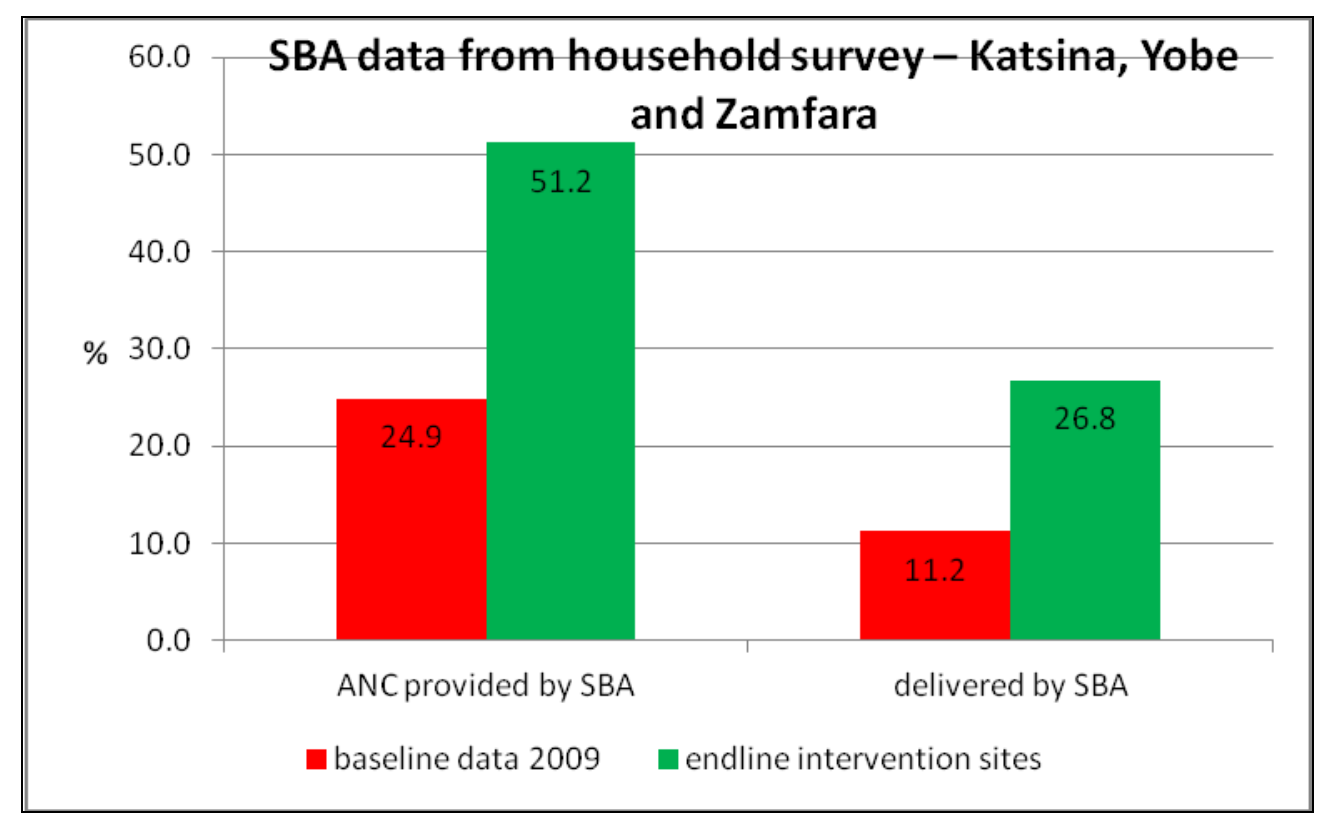

In terms of outcomes, the Nigerian Immunisation Coverage Survey (NICS) for 2010 reported major improvements across the whole country, apparently reflecting better organisation of routine immunisation and vaccine availability from NPHCDA. Results in most states where DFID has been supporting health sector reform were substantially better than the national average. In Jigawa, for example, coverage jumped from $0.1 \%$ in 2003, through $16 \%$ in 2006 to $76.6 \%$ in 2010 , among fully immunisation 1 -year olds. From being one of the worstperforming states in the country it rose to be the state with the 4th highest coverage, higher than any of the other 19 Northern States. 


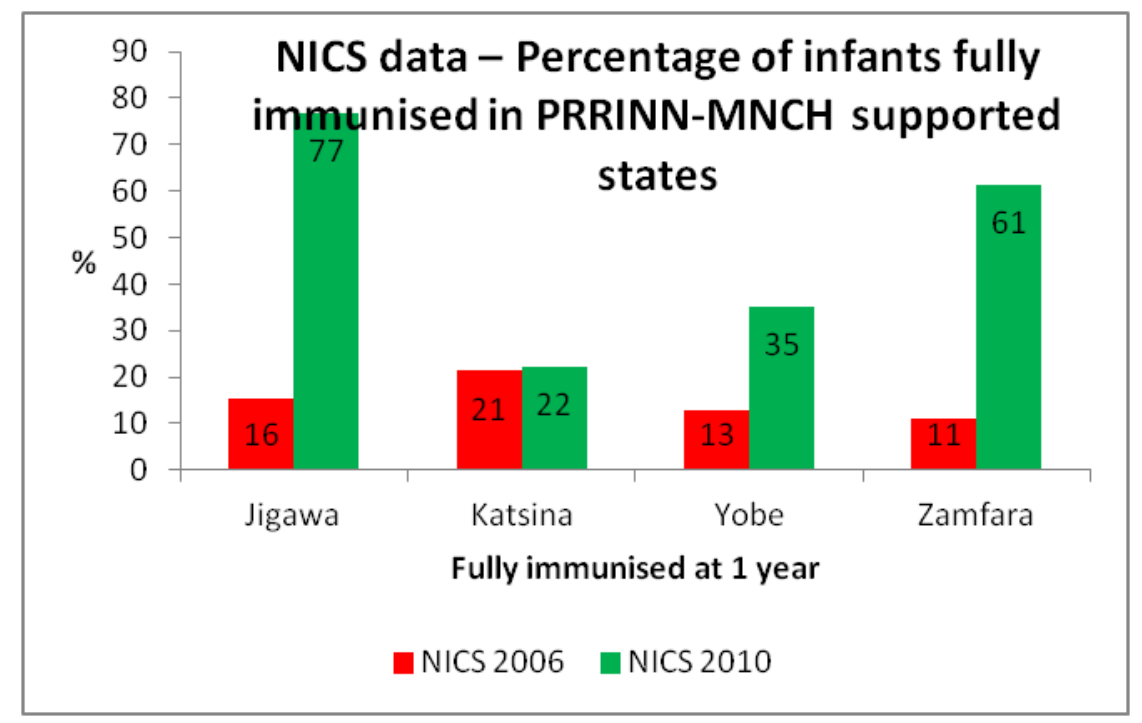

In terms of health indicators, the baseline (2009) and endline (2013) household surveys (HHS), conducted by Columbia University demonstrated remarkable improvements in infant and child mortality, with both rates almost halved.

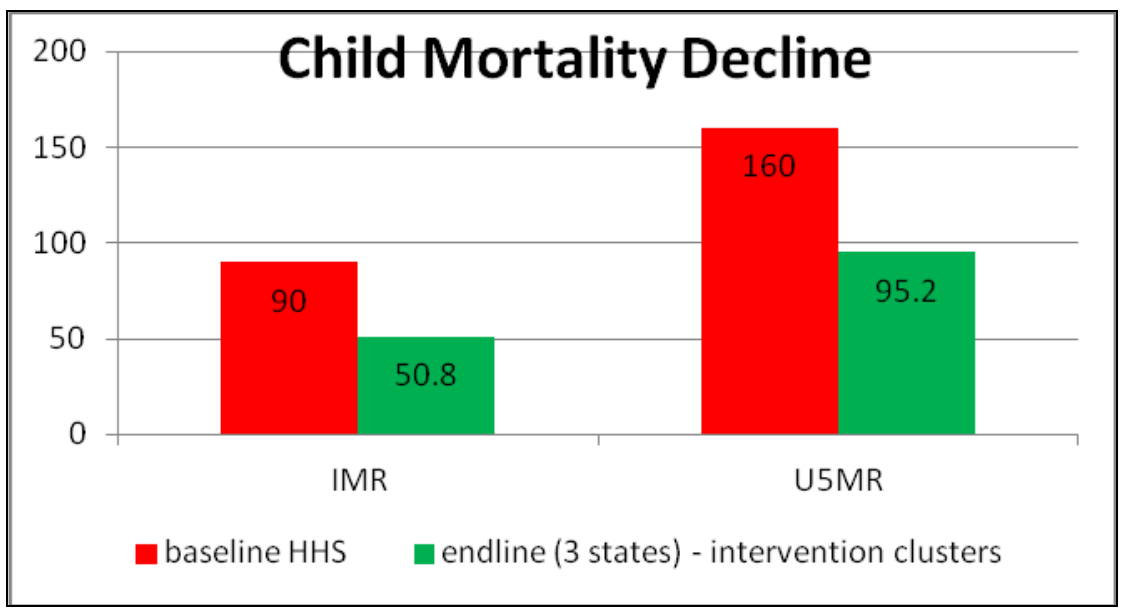

Improving maternal and child health indices and good immunisation coverage require, and is an indicator of, a well-functioning health care system, especially primary health care. It depends on effective routine services, inclusive of routine immunisation services (as opposed to campaigns), which in turn need functioning health facilities and delivery of reasonable quality and accessible services, so that mothers and children are attending clinics and health centres regularly. It also needs a flow of recurrent funding for the different levels of the health system and good management of finance, human resources, logistics and the supply-chain (for provision of drugs, vaccines etc.). Preferably there should also be community outreach services.

On another programme, the Malaria Action Programme for States (MAPS), we have supported a planning, budgeting and review process. The review uses proxy indicators ${ }^{8}$ to evaluate the effectiveness of the implementation of the annual malaria programme plans. These proxy indicators are starting to build a picture of significant progress in one of the states, Oyo (Johnson 2014). 


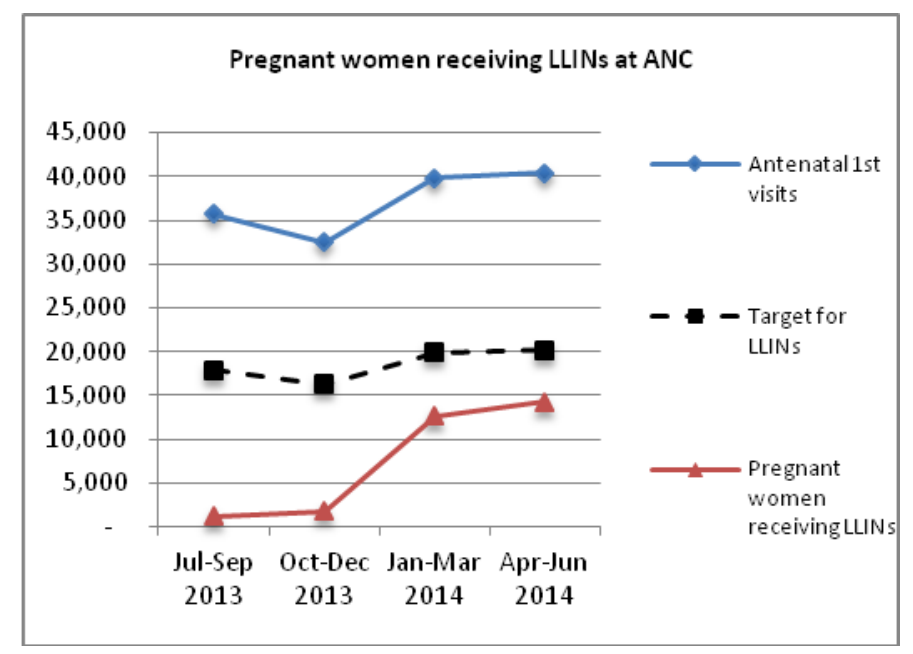

In the annual operational plan the key objective was to ensure that $50 \%$ of pregnant women attending ANC clinic receive LLINS (Long Lasting Insecticidal Nets) by December, 2014. Oyo has progressed from 7\% of target in $2^{\text {nd }}$ quarter of 2013 to $71 \%$ of target by June 2014 . Improved distribution systems now ensure that facilities have regular stocks available of LLINs and other commodities.

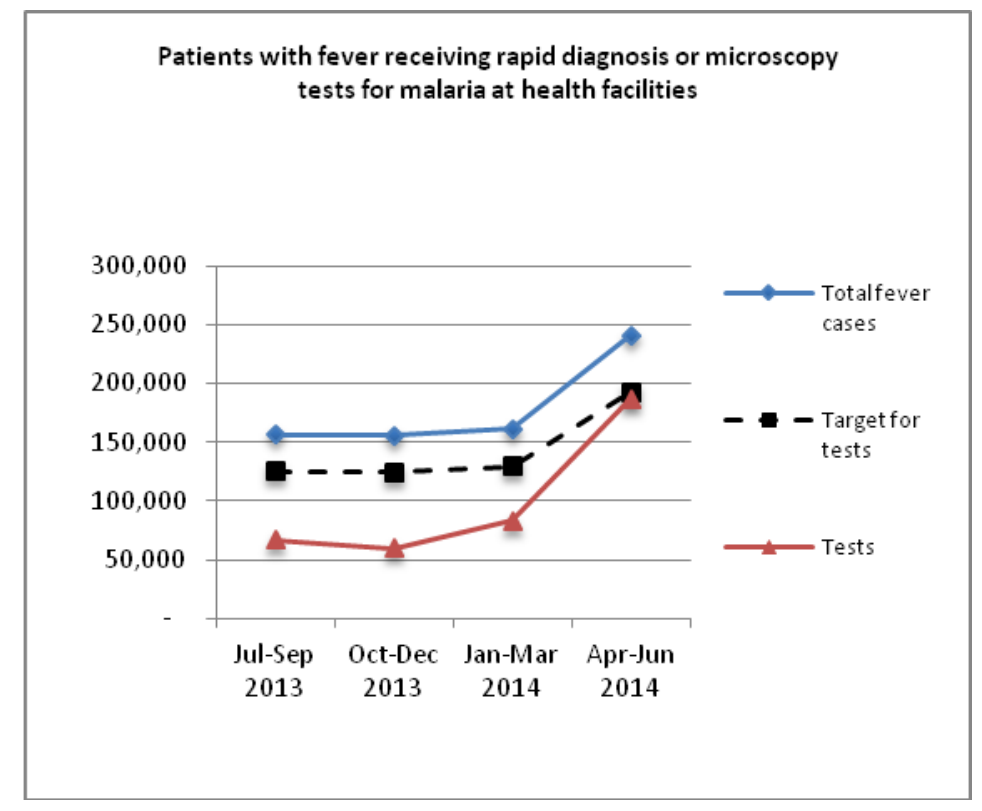

Similarly, another objective was to ensure that $80 \%$ of all people presenting with fever at the public health facilities have a diagnostic test done for malaria by December, 2014. Oyo has now reached $97 \%$ of its target. Oyo prioritises reliable diagnosis, because of its importance both for patient care, and for understanding the prevalence of malaria across the state.

\section{Lessons learnt}

Lessons learnt from the three approaches described, an appropriate and ongoing engagement approach; integrating governance reform with systems strengthening; and building policy-maker and community support for systems strengthening, include: 


\section{i) An appropriate and ongoing engagement approach}

This is often a very neglected and poorly considered aspect. Four interlocking issues are considered:

- Very careful attention to engagement is needed with stakeholders at many levels affected by reforms. These are the stakeholders (e.g. politicians, government administrators and health professionals, community and religious leaders) who must lead and implement the reform process or initiatives. This engagement is at the heart of any systems strengthening, but it is not automatic nor simple to execute. It requires viewing the situation through the complex adaptive systems lens, very careful planning and methods of engagement, as well as constant attention.

- Capacity to respond flexibly to local conditions and grasp opportunities for addressing core elements of health system functionality, as they emerge. Often, investing partners are constrained by funding proposals and plans when the situation cries out for an alternative approach or methodology. For example, the draft Health Bill promised substantial financial resources to those states that created SPHCBs. This drove the National Council for Health to adopt the "Bringing PHC under one roof" initiative and create SPHCBs. All this work was supported by the PATHS and PRRINN$\mathrm{MNCH}$ programmes.

- Appropriate technical support is required. Health managers battling on their own can't find the time, energy and resources to carry forward major reforms or to identify and assess the best options to pursue. Thus, access to capable, supportive technical assistance and shared experience from similar situations can be very valuable. Getting the right type of technical assistance can be challenging. Often the technical assistance provided is inappropriate for local conditions, amateurish and unskilled, undermining of local initiative, self-serving and self-perpetuating.

Development partner projects have been the main source of such support, but it is a more appropriate role for national and sub-national agencies and bodies (both public and private sector). If these bodies, or individuals, had the resources they could play a significant role. It is critical that development partner funding is utilised to strengthen these local bodies. For example in Nigeria, the emergency transport system work in overcoming the second delay in access for mothers with an obstetric emergency benefitted significantly from the close association with the National Union of Road and Transport Workers (NURTW).

- Hard sustained work establishes credibility. Many people believe that they can come in, spend some time and that all challenges will be addressed. Our experience is that you need senior, experienced support over a long time to make a difference. This should include a mix of both local and international people to combine contextual knowledge with external experience. Stakeholders on the ground won't trust you, let alone listen to you, until you have served some time, paid careful attention to those directly facing the problems every day, understood the complexity of the issues, etc. Turning systems around needs the kind of sustained input that often is not allowed for. It is also important to realise that important systemic changes will suffer setbacks. There are good reasons why the existing system works the way it does; yet we want to change this. Thus, while on the surface it makes sense to improve and make a better functioning, more efficient health delivery system, this is not necessarily what the power-brokers want (although they would never admit this). So substantial reforms inevitably require a sustained struggle with very careful strategising, some inevitable setbacks and above all persistence. 


\section{ii) Integrating governance reform with systems strengthening}

This link is seldom made and there are usually different people working on improving different management systems to those working on governance issues. Often a purely technical approach to systems strengthening is adopted. However, all the critical systemic issues in managing health services (e.g. budget allocations and disbursement, staff management, drug procurement and distribution, and capital investment) have significant governance elements. These need to be understood and then strategies adopted to improve systems in the context of the prevailing governance milieu or, where necessary, initiatives need to be developed to ensure necessary governance reforms. Strengthening systems requires technical skills and governance nous. For systems strengthening, it is equally critical to build political and institutional commitment to change, with strong local ownership integrated into locally-developed strategies and frameworks, as it is to institute technical systems strengthening changes.

In Nigeria, and arguably in many other countries, a key governance reform necessary to strengthen and build resilient health systems is reducing fragmentation.

Nigeria's efforts to improve health services were continually undermined by structural and institutional weaknesses. Fragmentation of the health sector, including management of services, staff, funds and other resources, can be considered as the most significant problem facing the country's health care services. Accountability mechanisms are weak and the quality of health services suffer. Communities have little confidence in services and use of them is usually very low. Thus, efforts to improve governance and strengthen systems in Nigeria are complicated by the fragmentation of healthcare systems and resources. Vertical programming and fragmented services are an anathema to those promoting an integrated approach to health care delivery.

It was the PATHS reform initiative that introduced the integrated district health system in Enugu and the "Gunduma" health system in Jigawa, both of which are very far-reaching changes to the governance and organisation of health services in each state. By engaging with stakeholder across multiple dimensions, technical, organisational and political, major changes were enacted in control and management of services, human resources and financial resources (PRINN-MNCH 2013). More recently this has been taken forward by the PRRINN-MNCH Programme as "bringing PHC Under One Roof" (PHCUOR) in Yobe, Zamfara as well as Katsina States. NPHCDA is now championing PHCUOR as a national initiative and in 2011 it was adopted as Nigerian policy by the country's National Council on Health. PHCUOR is modelled on WHO's guidelines for integrated district-based service delivery and includes the following major changes in health sector governance and functioning:

- $\quad$ Principle of 'three ones' (one management body, one plan and one monitoring and evaluation system)

- Single management body with control over services and resources (especially human and financial)

- Enabling legislative and regulatory frameworks

- Decentralised authority, responsibility and accountability with an appropriate span of control

- Integrated supportive supervision system managed from a single source

- Integration of all PHC services under one authority

- Effective referral system across the different levels of care

These changes provide the indispensable foundation on which effective health service delivery is now being built. 


\section{Key messages from the Northern Nigerian experience on reducing fragmentation}

include

- Integrating health care delivery systems enhances coordination, collaboration, effectiveness and efficiency as well as eliminating constraints, fragmentation, managerial uncertainty and wastage of resources.

- Restructuring health systems is a time-consuming task

- Understanding health systems as complex adaptive systems is key to health systems transformation.

- Reducing fragmentation and strengthening systems improves health indices.

- Establishing clear institutional relationships between the stakeholders (consumers, providers, decision-makers), and increasing the accountability and responsiveness of organisations to their consumers ensures sustainability.

Many fragile countries are overwhelmed by fragmented health care delivery systems which facilitate duplications, wastage and allow for political enterprise to obfuscate efficient and effective health care delivery systems. Thus, to build resilient health systems it is important to tackle fragmentation.

Other issues to consider in integrating governance reforms with systems strengthening initiatives include:

- $\quad$ Strengthening management capacity, especially through a work-based, problembased, mentoring approach, is key for adaptability and transformation, replicability and sustainability - key features of resilient health systems. Governance reforms often create new management cadres that require capacity building. Capacity building needs to address know-what (individual knowledge), know-how (individual skills), know why (organisational systems) and care-why (individual and organisational attitudes) if it is to be effective.

The system-wide population health re-orientation needed to sustain PHC ...will only become a lived reality when the front line staff who work at the health system's interface with the population bring it alive within their everyday routines and practices;... New forms of middle manager (and wider) leadership are required to nurture collective sense-making around $\mathrm{PHC}$ goals and empower front line health staff to take ownership of these goals, and so exercise their discretionary power in their pursuit; ...Mind-set changes, focused on concern for the population being served, the broader social determinants of health, and a willingness to act, are likely to be the fundamental basis for strengthening and sustaining PHC. In a complex adaptive system "...organisational change is not management induced. Instead, organizational change is emergent change laid down by choices made on the front line," (Weick 2009). Nurturing such change at the front line of the health system requires, therefore, new forms of leadership that enable sense-making in support of change and unleash the collective power distributed across the system towards shared goals.

(Gilson L et al http://www.health-policy-systems.com/content/12/1/30 )

- Attention to coverage and scale-up from the beginning. Time and again pilot projects targeting a few localised areas (e.g. local governments, districts) have not led to significant scale-up. A broader or whole-state/regional approach is vital for realistic transformation and replicability. Within this broader approach, experience points to the value of "emphasising a knowledge culture" and creating space for local innovation and assessment, communication and learning. In the PRRINN-MNCH programme, a 
Demographic Health Surveillance Site, a member of the InDepth Network, was created at Nahuche in Zamfara. This allowed for ideas to be tested and where considered appropriate rolled out across the broader 'practice area'.

- Adopting a sectoral approach to governance reform and systems strengthening. Our experience suggests that the struggle for reform may be easier within a sector such as health, rather than across the whole of government. We have found that key players have been prepared to give ground on a limited portion of their finance, staff, structure, systems, etc., in the expectation of fairly tangible, popular benefits (e.g. better health care or education services). Changes of this nature across the whole of government would pose a far greater challenge to entrenched interests - although there are indications that change in one sector can start to spread to others.

- $\quad$ Private versus public management of services. In many fragile states, health services are provided by a mix of private, public and not-for-profit bodies. Key challenges emerge as the fragile state moves from a humanitarian focus to a developmental focus. The public sector naturally wants to take over the delivery of health services. However, this is not that easy as the state lacks the capabilities to do this and if the process is too quick it can negatively impact on health service delivery. A more pragmatic approach might be to leave the health service implementation in the current hands and build the managerial capacity and systems of the state. Once these have proved sufficient in terms of developing and implementing policy, supporting service delivery providers, and in monitoring and evaluating service provision, then consideration can be given to a phased handover of service provision.

- The critical importance of strengthening finance and HR systems cannot be overemphasised. Key aspects include:

Finance: inadequate funding and release of budgeted resources. This is a recurrent problem largely due to poor fiscal projections and overbudgeting, often for political reasons. This allows key political figures to 'cherry pick' projects for support. Specific systems strengthening activities to tackle these issues include:

- broad FMS strengthening, inclusive of building planning and budgeting teams, introducing budget codes, supporting expenditure review processes;

- building the capacity of managers to, for example, draft memos, another challenge affecting budget release;

- creating specific pooled funds e.g. in Zamfara state, Nigeria, the basket fund was adopted to pool and increase funds for immunisation and PHC in general and in Jigawa, a pooled fund was created for similar purposes but addressing both PHC and $\mathrm{SHC}$;

- strengthening the capacity of government to manage and account for specific funds e.g. GAVI funds.

Lack of political will to effect necessary human resource changes. Political interference in the placement of health workers often leads to a poorly distributed workforce. When combined with the long-standing problem of ghost health workers, rural health facilities face grave shortages of suitably trained staff. To address this challenge, we described earlier the methods adopted which included the creation of a functioning HRIS and the establishment and strengthening of a high-level HR committee in each state where we worked in Nigeria.

- The right number of initiatives/activities. Although we have argued for a broad-based approach to build resilient health systems, it is critical to identify the appropriate number of activities that need to be done. This is context specific and constantly changes. The 
following example illustrates this dilemma and the need to adapt and expand initiatives as information becomes available:

Increasing the number of facility deliveries. On the PRRINN-MNCH programme the data showed increasing immunisation coverage and increasing ANC attendance but this was not matched by increasing facility delivery which had increased but not to the same degree. Thus, it was vital to understand why women are attending for antenatal care (ANC) and immunisation but not necessarily for delivery. The programme explored such questions as 'What will make you deliver in facilities?'. This led to initiatives such as making facilities more delivery friendly, increasing the number of skilled birth attendants (SBAs) at facilities through increasing the numbers of SBAs trained, exploring different retention strategies, supporting SBAs in the field, advocating for incentive packages for rural postings and so on.

\section{iii) Building policy-maker and community support for systems strengthening}

To build resilient systems, communities and policy makers need to be fully involved. This is an area that is often neglected. Key issues include incorporating community structures and systems and sharing information. Our experience, in Nigeria particularly, leads us to share the following lessons:

- $\quad$ Strengthening traditional social support mechanisms. In Nigeria, ground-breaking work on the clustering of morbidity and mortality among women who lack support and respect within the household led to the resurrection of social support mechanisms that specifically target these groups. Advocacy to traditional and religious leaders and training of health workers on the clustering effect have supported the process of reviving traditional social support mechanisms and targeting health worker initiatives at those most in need.

- Inadequate collaboration with religious leaders. Besides the clustering work mentioned above, the Nigerian programmes have collaborated with religious leaders in other areas (e.g. communicating messages around the need for women to attend ANC and deliver in a health facility, identifying young girls who are suitable for health worker training). This collaboration has led to a much better acceptance of the systems strengthening initiatives promoted.

- Maintaining volunteerism. A study into volunteerism undertaken by the PRRINNMNCH programme in 2012 found a high level of retention and self-motivation among volunteer community health volunteers working in the four programme states, the majority of whom stated that their primary driver was to "help others and save lives". Most of the volunteers indicated an intention to continue volunteering in future: they could see at first hand the positive effects of their volunteering efforts in terms of a reduction in maternal and newborn deaths in their communities and reported that they had gained respect in the community. This strategy of leveraging volunteerism in support of $\mathrm{MNCH}$ is often threatened by other initiatives which have introduced financial and other incentives for community health volunteers.

- Communicating information. The public health system is very weak on capturing, collating, analysing and utilising data both for management purposes and for advocacy purposes to government and communities. This is an issue that cuts across all sources of information (e.g. routine health management information system (HMIS) data, financial systems and human resource systems data). A variety of systems strengthening mechanisms need to be adopted to overcome this challenge and ensure that policy makers and communities have access to appropriate information: 
- For routine HMIS data, assistance can include resources (e.g. providing data collection tools, computers), training, data quality audits and review workshops. In Nigeria, one of the key initiatives was introducing the web based DHIS2 which allows real time data to be seen and compared. This galvanised health service managers to ensure the accuracy of the data that is generated routinely.

- On the programmes we have worked on, financial and human resource data has been captured, analysed and used for advocacy purposes, leading to changes in distribution and employment patterns of health workers and improved budget performance.

- A focus on developing costed plans with a linked monitoring and evaluation (M\&E) framework ensures that during regular reviews service and financial data are used to track progress.

- MSP work has combined these three sets of data (routine, finance and HR) and allowed a more rational planning process to emerge.

- Finally, the capacity building programme for managers has incorporated an emphasis on managers using data in their day-to-day management tasks.

\section{Way forward}

As indicated above, the results show progress. But, the question is how was this progress achieved? This question is related to a recent presentation at the Health Systems Research conference in Cape Town, September 2014.

In this presentation, one of the key problems identified with regard to $\mathrm{PHC}$ performance was

the 'black box'. We have gotten pretty good at measuring outputs like women with skilled birth attendance, and kids with diarrhoea that get oral rehydration solution (ORS)... and outcomes like maternal and child mortality....and we measure inputs into the systems -things that are pretty easy to measure like amount of money spent, number of health workers, number of clinic buildings. But there is still a big black box. What is it that really makes a primary health care system work so that the money and drugs and supplies and buildings actually lead to healthier people.

(R4D satellite session: the PHC Performance Initiative at the Health Systems Research Conference, Cape Town, September 2014)

Our assertion is that to make a PHC system work means investing in building a resilient health system through broad-based interventions, sufficient political will, "flexible" resources (as compared to rigid aid or usually inflexible government funding) and continuity over a significant period - preferably 10 to 15 years. Together with the broad-based health systems strengthening approach, this is the key message needed to build resilient health systems in fragile countries.

Based on the experience from Nigeria and other contexts, key steps that should be taken to build resilient health systems include:

i. Policy dialogue to build political commitment from affected country governments and international organisations and governments. This dialogue should be based on an analysis of the political economy of the country. The dialogue needs to be ongoing and should influence all the other key steps described below.

ii. Development of comprehensive plans to build resilient health systems in the affected countries. The plans need to be aligned with potential funding sources and include measures to address safety nets for the poor. 
iii. Consideration of the potential reorganisation of health services to reduce fragmentation, possibly utilising the district health approach as embodied in the PHCUOR principles described above.

iv. Agreement on the appropriate minimum service package to be provided at all levels. These should be costed to enable linkages with current and potential resources.

v. Early consideration to mobilise and commit experienced technical assistance to build the needed resilient health systems

vi. Develop and agree plans to strengthen specific components of health systems along the lines of the six (plus one) WHO HSS building blocks. This should include strengthening of the M\&E, surveillance and regulatory systems; improving workforce capacity - both technical and managerial capacity and including task shifting issues; strengthening financial management and supply chain management systems; and building community engagement and empowerment frameworks so that people are able to contribute to decisions concerning their individual health and that of their communities.

vii. Agree on joint review and monitoring systems to promote accountability and transparency and to be able to adjust activities as and when needed.

At the same time as global efforts are being focussed on addressing the Ebola crisis, resources need to be allocated to focus on the steps as outlined above.

Thus, coming back to the question of the health system in post Ebola West Africa, experience in the fragile circumstances of Northern Nigeria and South Sudan point to the importance of systems thinking even before the epidemic has abated. Thinking deliberately about how the health system in these countries might behave, given the complex adaptive systems analysis, should inform how hospitals are built, staff trained, systems strengthened. Current efforts to "bolt on" isolation wards, surveillance systems and more meticulous infection control procedures, though well intended, run the risk of inducing adverse unintended consequences. An approach grounded in understanding the CAS will focus on how individuals work with systems in institutions to align the complex set of resourcesmaterial and human - necessary to build the resiliency necessary to mount a durable response. The current epidemic will be halted and in itself this is a good thing. However, it is critical from the very beginning to think of how resilient health systems can be built in those countries most affected by the Ebola crisis and with the most fragile health systems. If this is not done, then the likelihood of another crisis rearing its head in the future is highly likely.

\section{Conclusion}

...(In Nigeria) an emergency command center ...(was built) in 2012 to survey the presence of polio in the region, and the existing system helped enable the country to proactively contain the spread of Ebola. Utilizing emergency operations, healthcare personnel in Nigeria had confirmed 19 cases of Ebola, as well as one probable case, Reuters reported. By Sept. 24, officials had identified 894 contacts with those cases and conducted 18,500 visits with those who'd potentially been infected to check for Ebola symptoms. In the weeks since, no new cases have emerged.

(Robbie Couch, The Huffington Post 2014)

While it is necessary to have an effective surveillance system, this must be seen as an integral part of a resilient health system which is the first prize. 
Much like cholera preys on weak water systems after a disaster, Ebola is preying on a weak public health system after years of conflict and upheaval in Liberia. And health system performance in many partner countries is challenged by critical health worker shortages, inadequate financing, poor or disjointed information systems, lack of essential information on public health threats, and inexperienced leadership. (http://blog.usaid.gov/2014/10/at-the-heart-of-ebola-health-systems-that-needstrengthening/ )

It is critical that in building a resilient health system, that all the institutional knowledge emanating from the lessons learnt above enable frontline health workers to provide more effective health services. System strengthening activities, e.g. planning, supervision, strengthening supply chain management, need to be allied with capacity building and empowering frontline health workers. In this way resilient health systems are built, nurtured and maintained.

The focus of this policy paper has been on strengthening resilient health systems. But, health system resilience is essential for sustainable equitable access and this should contribute to people's good health and therefore be one factor in building individual resilience. Health system resilience will also contribute to a country's resilience as the system will be able to respond to shocks such as epidemics, conflict, natural disasters, economic crises etc. 


\section{References}

Adam, T. (2014) Advancing the Application of Systems Thinking in Health, Health Research Policy and Systems 2014, 12:50 http://www.health-policy-systems.com/ content/12/1/50

Ager, A. et al (2014) Systems Dynamics Analysis of Health Systems Resilience: Case Studies from Cote d'Ivoire and Nigeria Poster presented at the Health Systems Research Conference, Cape Town October 2014

Anyebe, W.; Bezzano J. and Foot S. (2005) Country Level Testing: The Health Sector in Nigeria, An Analytical Framework for Understanding the Political Economy of Sector and Policy Arena Internal DFID Report

Barron, P.; McKenzie, A. and Kumba, J. (2007) Policy Note for Health: Better Intergovernmental Coordination in the Delivery of Health Services: Issues for Analysis, Internal DFID Report

Couch, R. (2014) Nigeria Has Successfully Contained Ebola, US Hopes To Learn From Their Response', The Huffington Post 10 September 2014

Dattee, B. and Barlow, J. (2010) 'Complexity and Whole-system Change Programmes', Journal of Health Services Research and Policy 5 (Suppl 2): 19-25

de Savigny, D. and Adam, T. (2009) Systems Thinking for Health Systems Strengthening, WHO, http://whqlibdoc.who.int/publications/2009/9789241563895_eng.pdf

DFID (2004) DFID Drivers of Change Public Information Note, London: Department for International Development

DFID PQQ for the Nigerian MNCH2 draft ToR (2013) Extract.

Enyimayew, N. and McKenzie, A. (2007) Developing Integrated and Decentralised Health Systems, PATHS end of programme documentation

Federal Ministry of Health (2011) National Health Bill

Federal Ministry of Health (2010) National Health Strategic Development Plan Federal Ministry of Health and World Health Organisation

Federal Ministry of Health: Health Sector Reform Program. Strategic Thrusts; Key Performance Objectives; and Plan of Action 2004 - 2007

Federal Ministry of Health (2004) Revised National Health Policy

Freinkman, L (2007) Intergovernmental Relations in Nigeria: Improving Service Delivery in Core Sectors, http://mpra.ub.uni- muenchen.de/10032/ 1MPRA_paper_10032.pdf (accessed 1 September 2011)

Freinkman, L. (2007) 'Inter-government Policy Coordination and Improvements in Service Delivery', in J.I. Elaigwu (ed.), Fiscal Federalism in Nigeria: Facing the Challenges of the Future, Jos, A. Aha Publishing; 1-21 
Gilson, L et al (2014) Advancing the Application of Systems Thinking in Health: South African Examples of a Leadership of Sensemaking for Primary Health Care, Health Research Policy and Systems 2014

Gilson, L. et al (2003) The SAZA Study: Implementing Health Financing Reform in South Africa and Zambia, Health Policy Plan. 2003 Mar;18.1: 31-46

Heymans, C. and Pycroft, C. (2005) Drivers of Change in Nigeria: A Preliminary Overview, DFID-Nigeria's Drivers of Change Initiative (July): 1-67; DFID internal document

Huma, H. and Rao, S. (2010) Political and Social Analysis for Development Policy and Practice: An Overview of Five Approaches, Governance and Social Development Resource Centre (September): 1-37

Johnson, R. (2014) Planning for Results - Annual Operational Planning for Malaria in Oyo State, MAPS programme internal report

Khemani, S. (2005) Local Government Accountability for Health Service Delivery in Nigeria, World Bank internal report

Leftwich, A. (2006) Drivers of Change: Refining the Analytical Framework, Department of Politics, University of York (April): 1-74

McKenzie, A.; Sokpo, E. and Ager, A. (2014) 'Bridging the Policy-implementation Gap in Federal Health Systems: Lesson from the Nigerian Experience', Journal of Public Health in Africa (2014), 5:381

Paina, L. and Peters, D. (2012) 'Understanding Pathways for Scaling up Health Services Through the Lens of Complex Adaptive Systems', Health Policy and Planning 27: 365373

Peters, D. (2014) The Application of Systems Thinking in Health: Why Use Systems Thinking?, Health Research Policy and Systems

Pourbohloul, B. and Kieny, M. (2011) 'Complex Systems Analysis: Towards Holistic Approaches To Health Systems Planning and Policy', Bull World Health Organisation 89: 242

PRRINN-MNCH (2013) Final Report see http://www.prrinn-mnch.org/resources-reportsannual.html

Rodin, J. (2014) The Resilience Dividend: Being Strong in a World Where Things Go Wrong, Rockefeller Foundation

SPARC and SAVI (2009) Political Economy Assessment - Jigawa State, Final Report, Internal SPARC and SAVI report

Varghese, J. et al (2014) 'Advancing the Application of Systems Thinking in Health: Understanding the Growing Complexity Governing Immunization Services in Kerala, India', Health Research Policy and Systems 2014, 12:47, http://www.health-policysystems.com/ content/12/1/47

Weick, K. (2009) Making Sense of the Organisation: The Impermanent Organisation, Volume 2, Chichester, John Wiley and Sons. As quoted in Gilson et al (2014). 
WHO (2007) Everybody's Business. Strengthening Health Systems to Improve Health Outcomes: WHO's Framework for Action, WHO Document Production Service, Geneva. http://www.who.int/healthsystems/strategy/everybodys business.pdf

Zhang, X. et al (2014) 'Advancing the Application of Systems Thinking in Health: Managing Rural China Health System Development in Complex and Dynamic Contexts', Health Research Policy and Systems 2014, 12: 44

Zhou, Y. Strengthening Local Governance in Nigeria: Issues and Options for the World Bank, World Bank internal document 